\title{
Habilidades e Estratégias para gerir a ansiedade antes e durante o recital: um estudo multicaso com pianistas estudantes e profissionais
}

\author{
Dayse Gomes Mendes
}

(UFPB)

\begin{abstract}
Resumo: O presente relato é o recorte de uma dissertação de mestrado cujo objetivo foi investigar as habilidades e estratégias de performance utilizadas por pianistas para gerir a ansiedade nas apresentações. A metodologia expôs um estudo multicaso, cujos participantes foram pianistas estudantes e profissionais de Recife-PE, os quais foram classificados em grupo 1: três estudantes de piano da Escola Técnica Estadual de Criatividade Musical (ETECM) e grupo 2: três pianistas profissionais, todos em fase de preparação para o recital. Apresentamos neste relato uma mostra dos resultados obtidos a partir de entrevistas semiestruturadas. Inferiu-se que tanto estudantes como profissionais apresentaram habilidades e estratégias eficientes para tocar com o mínimo de ansiedade. Porém, estes aspectos mostraram-se em diferentes níveis de conhecimento e desenvolvimento cognitivo.
\end{abstract}

Palavras-chave: Cognição Musical, Habilidade e Estratégias, Gestão da ansiedade.

ABILITIES AND STRATEGIES FOR MANAGING ANXIETY BEFORE AND DURING THE RECITAL: A MULTI CASE STUDY WITH STUDENTS AND PROFESSIONALS PIANISTS

Abstract: The present report is the snippet of master's degree dissertation whose objective was investigate the performance abilities and strategies used by pianists to manage anxiety at presentations. The methodology brought to light a case study, of the multicase type, participants of which was students and professionals pianists in Recife, Pernambuco, Brazil, which were classified as Group 1): three piano students at State Technical School of Music Creativity and, Group 2): three professional pianists, all of them in the stage of preparation for a recital. We present in this report a sample of the results obtained from semi-structured interviews. It was inferred that both students and professionals showed efficient abilities and strategies to play with a minimum of anxiety. These aspects, however, exist on different levels of knowledge and cognitive development.

Keywords: Music Cognition, Abilities and Strategies, Management of Anxiety 


\section{Introdução}

O presente artigo é o recorte de uma dissertação de mestrado intitulada “Habilidades e Estratégias para gerir a ansiedade antes e durante o recital: um estudo multicaso com pianistas estudantes e profissionais". Localiza-se na área da psicologia cognitiva musical que de acordo com Ilari (2009, p. 13), se entende por uma "área de natureza interdisciplinar e tem relação direta com as atividades do cérebro humano e suas formulações verbais, ou seja, o estudo da mente humana" e objetiva compreender os processos mentais relativos a uma variedade de comportamentos musicais a exemplo da percepção, compreensão, atenção e performance.

O objetivo geral desta pesquisa consistiu em investigar as habilidades e estratégias de performance utilizadas por pianistas para gerir a ansiedade nas apresentações. Neste sentido, realizou-se um estudo comparativo entre profissionais e estudantes em suas atividades nos últimos estágios de preparação pianística e comportamental para um recital. Já o processo de construção teórico consistiu em cinco ramificações temáticas, a saber, 1) ansiedade, 2) preparação para o recital, 3) concentração, 4) habilidades e 5) estratégias, as quais convergiram para embasar o conhecimento sobre a fenomenologia da preparação e execução da performance.

A investigação sobre o fenômeno da preparação para um recital, sob a perspectiva da cognição musical, é algo muito recente, pois pesquisas como as de Greene (2002), Kenny (2011), Wilson \& Roland (2002) e Williamon (2004) têm mostrado que é na observação dessas práticas que se adquire conhecimento sobre elas para que sejam promovidas orientações de melhoria nas apresentações musicais e não uma proposta de sobrevivência a esses eventos. Temas nessa linha de pesquisa já têm sido abordados por grupos de estudos criados especificamente para esse fim, conforme NUPSIMUS (Núcleo de Estudos em Performance Musical e Psicologia) ${ }^{1}$ e o GEPEM (Grupo de Estudos em Performance Musical). ${ }^{2}$

\footnotetext{
${ }^{1}$ Grupo inscrito no Diretório de Grupos do CNPq desde 1995, coordenado pela professora Diana Santiago e tem trabalhos que investigam a prática musical, ou seja, (preparação de estudantes de piano) publicados desde 2004.
} 
Compreende-se ainda que o processo de preparação para o recital é de extrema importância no estudo de um instrumento musical, pois é quando o músico, tanto estudante como profissional, se prepara para entrar em cena. Essa fase de aprendizagem inclui não apenas a apresentação pública, mas também os caminhos traçados pelo intérprete, suas motivações e estratégias utilizadas com o objetivo de otimizar seu desempenho. Segundo Ray (2009), mesmo que o músico possua qualidade, talento e sólida formação, é relevante a preparação ao lidar com a situação de palco e, quanto melhor for essa elaboração para a performance musical, menor será o grau de ansiedade.

Entende-se que a preparação para o recital e a amenização da ansiedade são processos estritamente relacionados. 0 primeiro requer fatores como 0 preparo seguro do repertório, ensaios, ambientação com o local, além da expectativa que o pianista tem em relação ao público e ao seu desempenho, podendo, desse modo, conduzi-lo a um estado de ansiedade. Esta, por sua vez, é uma sensação muito pessoal e apresenta sintomas físicos, mentais e consequências variáveis como falta de concentração e controle emocional, muitas vezes decorrentes da grande expectativa do momento em si, e da crítica da plateia, aspectos estes, causados pela imaginação do intérprete, que nem sempre condizem com a realidade.

No meio musical, os estudiosos ${ }^{3}$ utilizam o termo ansiedade da performance musical, compreendida também pelo medo de palco, ou seja, um exagerado e incapacitante medo de tocar em público na maioria das vezes. O estado de ansiedade tem sido documentado como problema para muitos artistas, com estudos que apresentam um índice em que $24 \%$ dos músicos de orquestra são regularmente afetados por ela, e 15\% encontram limitações graves para tocar em Concertos. Outro exemplo relevante é o de solistas ilustres e veteranos: Maria Callas, Enrico Caruso, Pablo Casals, Vladimir Horowitz e Ignacy Paderewski, os quais apresentaram sintomas de ansiedade de performance (WILLIAMON, 2004).

${ }^{2}$ O GEPEM, criado em 2002, por iniciativa da Professora, Dra. Sonia Ray, tem a maioria de seus membros docentes e alunos pesquisadores da Escola de Música e Artes Ciências da Universidade Federal de Goiás apesar de agregar também pesquisadores de outras instituições com pesquisas na mesma área e em áreas afins.

${ }^{3}$ Kenny, 2011; Wilson \& Roland, 2002; Fonseca, 2007. 
Por isso, uma área que tem recebido considerável atenção de pesquisadores e profissionais é a gestão da ansiedade de desempenho (WILSON; ROLAND, 2002), ou seja, a descoberta de meios que facilitem a exposição pública e o modo de administrá-los durante importantes eventos não utilizando betabloqueadores apenas. Ray (2009) sugere alguns recursos que minimizam a ansiedade nas apresentações, tais como, planejar o tempo de estudo, considerando as atividades extramusicais do dia, assistir a apresentações de outros músicos, estabelecer previamente metas individuais, realização de pré-recitais e ainda buscar prazer nos motivos que levaram o músico a ser um instrumentista.

Nesta pesquisa procurou-se indicar a direção benéfica das investigações sobre ansiedade por se acreditar que, antes de ser uma inimiga, esta é um sistema de proteção preparada para os desafios e os seus benefícios podem ser vistos depois que passa a situação de perigo, atuando como um mecanismo de adaptação (SANTI, 2012). Depreendeu-se que a ansiedade no recital está presente em profissionais e estudantes. As causas podem ser diversas, a exemplo do medo de julgamento, lembranças desagradáveis do passado e quantidade de expectadores.

\section{Habilidades e Estratégias}

A fim de introduzir ao procedimento metodológico, é importante distinguir entre o conceito de habilidades e estratégias. De acordo com Paula e Borges (2004, p. 31), "Não há dúvida de que o fazer musical exige do instrumentista capacitação específica, demandando que, durante sua formação, sejam adquiridas diversas habilidades que o qualificam para o exercício da performance". O treinamento musical é o meio de aquisição de habilidades específicas. A criança possui uma série de habilidades musicais como aprendizagem e memorização de canções e distinção de variedades musicais. À medida que ela cresce, são desenvolvidas novas habilidades, a exemplo de execução instrumental e vocal, composição e regência. Ninguém se torna expert em todas essas habilidades. 
mas em cada cultura há geralmente concordância quanto às habilidades que podem exigir de um 'músico completo', e esse conjunto de habilidades é institucionalizado nas rotinas de treinamento e de exames escolares e das faculdades de música (SLOBODA, 2008, p. 284).

O mesmo autor (2008, p. 285) aborda alguns conceitos gerais que são associados à aquisição de habilidades. Primeiro, "uma habilidade envolve a aquisição de hábitos". A principal característica de um hábito é seu automatismo e pouca ou nenhuma capacidade mental na sua execução. O comportamento consciente, deliberado e marcado pelo esforço, antecede aos hábitos que, geralmente, envolvem controle verbal. Em segundo lugar, "a aprendizagem de habilidades necessita da transposição de um conhecimento factual (saber o que) para um conhecimento procedimental (saber como)", ou seja, o conhecimento a respeito de uma habilidade é diferente de executá-la na prática, e "a aprendizagem refere-se justamente à compreensão da mudança de um conhecimento factual para um conhecimento procedimental". Nessa transformação, o conhecimento passa a ser controlado de maneira mais estreita e guiado por objetivos.

Outra condição fundamental para o aprendizado de habilidades é a repetição. No entanto, não é simplesmente repetir por repetir, mas, quando algum conhecimento é introduzido, deve ser conservado e assimilado na mente ao se aplicar com frequentes recorrências para evidenciar sua utilidade. As técnicas de ensaio e exercício são exemplos da necessidade de repetir. Os músicos profissionais afirmam que, normalmente, o progresso rápido só é alcançado mediante uma prática repetitiva, em que o aprendiz precisa encontrar formas de transformar um esforço desagradável em agradável ou, no mínimo, suportável. O tempo que o indivíduo passa realizando determinada atividade é um dos mais indicados meios de se prever seu nível de habilidade (SLOBODA, 2008, p. 298).

O processo de aquisição de habilidades pode ser dividido em três estágios: cognitivo, associativo e autônomo. De acordo com Anderson (1982 apud SLOBODA, 2008, p. 286),

O estágio cognitivo envolve uma codificação inicial da habilidade em uma forma suficiente para permitir que o aprendiz gere o comportamento 
desejado, pelo menos num nível de aproximação grosseira. Nesse estágio, é comum observar-se mediações verbais, em que o aprendiz repete as informações necessárias à execução da habilidade. O estágio associativo é aquele em que a habilidade passa a ser executada de maneira suave. Os erros na compreensão inicial da habilidade são sucessivamente detectados e eliminados. Concomitantemente, desaparece a mediação verbal. No estágio autônomo, há uma melhoria gradativa e continuada na performance de uma habilidade. Frequentemente, nesse estágio, as melhorias continuam indefinidamente.

Sloboda (2008, p. 301) explana que "não se cria aprendizagem oferecendo às pessoas fatos ou receitas, pois essas ofertas não têm utilidade, a menos que as pessoas possam incorporá-las aos procedimentos que já possuem". Seria como um livro, cujo conhecimento não será revelado enquanto permanecer na prateleira, da mesma forma os fatos não poderiam exercer influência real na habilidade. Sendo assim, o planejamento da aprendizagem é constituído de tentativas e erros. É impossível planejar um treinamento ideal, pois depende da competência que cada indivíduo adquire. Não é possível definir receitas infalíveis para uma situação em que o conjunto de regras de produção em um mesmo indivíduo não pode ser facilmente reconhecido. Cada aluno tem seu tempo e forma de aprender.

O maior fator do progresso em qualquer aprendizado é o próprio aprendiz, os procedimentos de que ele dispõe e as motivações que apresenta. Mesmo em um ambiente escolar, onde as condições de aprendizagem sejam favoráveis, o aprendiz não consegue controlar por completo o seu progresso, pois algumas coisas são mais fáceis que outras, ainda sim, a motivação e concentração estarão presentes na superação de uns obstáculos, mas não em outros. Dessa forma, o aprendiz observará seu próprio aprendizado, às vezes com satisfação, em outros com desespero.

A atitude dos bons docentes e discentes deve ser "construir um estoque de fatos frequentemente observados acerca dos ambientes de aprendizagem e da organização do tempo que, no todo, funcionam bem para eles" (SLOBODA, 2008. p. 302). À medida que o estudante torna-se mais experiente, as condições ambientais também proporcionarão um conhecimento único para esse indivíduo e 
ele compartilhará uma herança proveniente das propensões biológicas com as experiências da enculturação. ${ }^{4}$

No contexto musical, os alunos mais bem motivados aprendem quando Ihes são oferecidas oportunidade e possibilidade. A motivação para aprender determinado conhecimento parece ser forte o suficiente a fim de que os alunos desenvolvam a autoaprendizagem. Os professores dão suporte a esse processo proporcionando informações e feedback, para que a aprendizagem seja contínua e o aluno se defronte com os aspectos musicais que vão sendo introduzidos e assim os acoplem a sua experiência.

Sternberg (2008, p. 392) apresenta pesquisas sugerindo que a diferença entre especialistas e novatos está na quantidade, na organização e no uso do conhecimento. Outros estudos examinaram especialistas em diferentes domínios. O que diferenciou profissionais de estudantes foi seu esquema para resolver problemas dentro de seus próprios domínios de especialização (REITMAN, 1976; LESGOLD et al., 1988; LARKIN et al., 1980). Os esquemas dos especialistas envolvem grandes unidades de conhecimento, altamente interconectadas, organizadas segundo semelhanças estruturais subjacentes entre unidades. Em comparação, os esquemas dos novatos envolvem unidades de conhecimento relativamente pequenas e desconectadas, organizadas segundo semelhanças superficiais (BRYSON et al., 1991 apud STERNBERG, 2008).

Para os profissionais, muitos aspectos da solução de problemas podem ser comandados por processos automáticos. Esse automatismo geralmente facilita a capacidade de resolver problemas em dada área de especialização que, em geral, converge para a solução correta com base na gama de possibilidades. A especialização em determinado domínio é vista em grande parte sobre a perspectiva de que a prática leva à perfeição (STERNBERG, 2008).

Já o conceito de estratégia, segundo Sloboda (2008), consiste em quebrar a habilidade a ser aprendida em um conjunto de componentes que podem ser

\footnotetext{
${ }^{4} \mathrm{O}$ conceito de enculturação musical se refere à aquisição de habilidades e conhecimentos musicais por imersão na música cotidiana e nas práticas musicais de um dado contexto (GREEN, L., 2001).
} 
adquiridas passo a passo. Para determinado comportamento de aprendizagem, há aplicação de um conjunto de estratégias bem gerais, as quais conduzem ao aprendizado e visam ao domínio de qualquer tarefa. Também pode ser definida como a "arte de aplicar os meios disponíveis ou explorar condições favoráveis com vista a objetivos específicos" (FERREIRA, 2001).

O músico que tem prática e experiência em uma habilidade particular tem qualificação para pensar em esquemas de treinamento, por isso há muitas maneiras possíveis de segmentar uma atividade, ou definir estratégias de acordo com as necessidades de cada um. É mais importante a assimilação do princípio de segmentação que a imposição de algum esquema como o melhor de todos (SLOBODA, 2008).

Wenstein \& Mayer (1986 apud JORGENSEN, 2004, p. 85) discorrem que "estratégias de aprendizagem são pensamentos e comportamentos utilizados pelos músicos durante a prática, as quais influenciam o estado motivacional e afetivo, ou o modo como eles selecionam, organizam, integram e ensaiam novos conhecimentos e habilidades". Jorgensen (2004) dá o seguinte exemplo: quando o músico planeja a sua prática, é uma estratégia de pensamento, e o aumento gradual do andamento de uma partitura é uma estratégia de comportamento. Acrescenta ainda que as estratégias, mesmo conscientemente aplicadas, podem tornar-se automáticas. Apesar da diversidade de estratégias existentes, há aquelas comuns que os músicos podem empregar para produzir melhor resultado de prática ou, ainda, alcançar os mesmos resultados com rapidez.

Jorgensen (2004) destaca que professores de música têm sugerido aos alunos a prática "autorregulada", em que, ausentando-se o orientador, os estudantes devem ter autonomia para planejar tarefas definidas e supervisionar sua própria prática. $\mathrm{O}$ autor aborda que há três fases de aprendizagem para a prática instrumental eficaz: Planejamento e preparação da Prática, Execução da Prática, Observação e Avaliação da Prática. As respectivas fases de prática são entrelaçadas e cíclicas.

Direcionar a atenção do instrumentista a essas três fases a serem empregadas na prática não é, contudo, suficiente para uma utilização eficiente das estratégias individuais. Cada praticante, do estudante ao profissional, deve ter um 
conhecimento perfeito de seu repertório e das estratégias que utilizará para controlar, regular e utilizar esse repertório. De fato, estudantes e profissionais muitas vezes têm opiniões próprias, o que constitui uma prática eficaz. Apesar dessa diversidade, existem estratégias comuns que os músicos podem empregar a fim de produzir melhor resultado de desempenho ou alcançá-lo com mais rapidez.

Jorgensen (2004) discorre sobre algumas estratégias utilizadas em variados estágios da prática instrumental. São elas: 1) Estratégia para a prática individual, de planejamento e preparação; 2) Estratégias de ensaio e subdivide-as em estratégia mental versus estratégia de ensaio tocando, de domínio de toda a peça versus partes menores 3) Estratégias de preparação para a apresentação pública e 4) de avaliação. Outras pesquisas abordam a respeito de várias estratégias de estudo, porém destacamos a seguir algumas das quais julgamos auxiliarem à amenização da ansiedade no palco, como as propostas por Sloboda (2008), Jorgensen (2004), Greene (2002) e Cardassi (2000).

\section{Estratégia de simulação para um recital}

Toda atividade musical é projetiva, isto é, o indivíduo faz conforme se mostra; logo, permite que o observador treinado veja tanto os aspectos que funcionam bem no indivíduo como aqueles em que entra em conflito. Tais aspectos observados e analisados permitirão ao professor organizar uma estratégia de ensino e elaborar seu plano de aula (GAINZA, 1988).

Em seus experimentos sobre psicopedagogia, a autora dá um exemplo na sua prática de ensino de piano a alguns alunos inibidos: 'Toque forte, se passar da medida, eu aviso'; ou alguém com problema de expressão: 'Faça pose de artista, sinta-se como um cantor no teatro'. O aluno pensa: 'na realidade, eu só sou aquilo que represento' e, dessa forma, fica mais fácil de o aluno compreender o que se pede. Com essas expressões sugeridas, ela pretende que o aluno perceba certo tipo de relação frequentemente reprimida que existe entre o instrumentista e seu instrumento (Idem, 1988). 
Greene (2002) compara o passo a passo da simulação de um recital com um processo semelhante a uma aula de instrumento. Ao conhecer um novo professor, o estudante pode expressar sentimentos bons ou maus e, assim, tentar eliminar as dificuldades. Daí o músico começa a tocar e o docente consegue diagnosticar problemas, oferecendo soluções e atribuindo exercícios específicos para suas necessidades. O autor orienta o músico a se preparar para o seu recital. Ele projeta um roteiro para trabalhar ao longo de um período de três semanas. Como parte desse treinamento, o músico simula duas performances ao vivo, gravadas de preferência, até culminar no evento importante. Nessas simulações, é importante que professores e/ou amigos estejam presentes, o que pode ser favorável e também gerar alguma ansiedade.

Além disso, o músico deve planejar metas para cada peça do repertório, descritas numa ficha, a fim de se acompanharem os resultados. O repertório escolhido não precisa ser o que será apresentado na íntegra no dia do recital e orienta o intérprete a fazer comentários na própria gravação. Caso ele não se sinta satisfeito com o resultado, pode criar alternativas. ${ }^{5}$

\section{Estratégia de recuperação}

Segundo Greene (2002), há duas situações críticas com as quais o músico de sucesso deve lidar excepcionalmente bem: os primeiros momentos do recital e os momentos após os erros. As duas situações exigem estratégias completamente diferentes. Considerando que o músico tem dias, meses e, em alguns casos, anos para se preparar, os erros não são planejados. Os erros "apontam" algo não executado corretamente. Muitas vezes anunciam o nível mais baixo de suas habilidades, mas visam direcioná-los aos melhores aspectos, ou seja, os erros também podem servir para delinear o pico das habilidades do músico. "Os erros são, portanto, uma influência benéfica de 'empurrar o envelope', de perseguir seu

\footnotetext{
${ }^{5}$ Cardassi (2000, p. 253) sugere "A utilização de uma ficha com a definição dos objetivos (agrupados em técnicos, musicais e pessoais), evidenciando os pontos conquistados a cada simulação, e outros ainda a serem melhor trabalhados".
} 
ideal [...] nossas faltas e erros fornecem marcos para nossas capacidades mais elevadas" (GREENE, 2002, p. 90).

$\mathrm{O}$ referido autor relata que, se o instrumentista estiver atuando em um estado de alta concentração, compromissado em ir além, poderá cometer erros ocasionais. Estes são recomendados, pois, dada a complexidade das habilidades de performance artística, executada em circunstâncias de muito stress, os erros não serão apenas normais, mas inevitáveis. Greene sugere que o músico deve se permitir faltar uma nota de vez em quando, a menos que ele tente evitar erros a todo custo. Somente quando ocorrem erros posteriores é que se percebe que nem tudo foi bem sucedido.

A seguir, Greene (2002) sugere algumas estratégias de recuperação:

Aceitar o erro. Contentar-se com a realidade da falha não significa que o músico deva fazê-lo com sorriso no rosto. Apesar da fúria nesse momento, essa emoção não é relevante. A avaliação do recital, inclusive os possíveis erros, deve ser feita após a apresentação, não sendo por isso necessário o intérprete deixá-los visíveis ao público.

Retornar ao presente. Quando a mente rememora a causa do erro ou a preocupação com passagens difíceis na peça, o foco diminui. Após o erro, é importante trazer o pensamento de volta para o presente rapidamente.

Relaxar os músculos. Erros frequentes causam músculos contraídos. O músico deve utilizar o erro como sugestão para lembrar-Ihe a liberação do excesso de tensão, especialmente se sentir raiva. É necessário garantir um corpo flexível e acessível aos momentos de musicalidade.

Tocar em nível razoável. O autor relata que já observou muitos artistas profissionais tentarem compensar os percalços utilizando algumas proezas, mas essa atitude tende a aumentar o problema. $\mathrm{Na}$ intenção de compensar notas ruins com grandes notas só provocará mais notas ruins, ou seja, a tentativa de realizar exibições não previstas pode ser um desastre. Segundo Greene, "é cavar-se em um buraco profundo" (p. 92). O músico deve concentrar-se no processo de fazer "muito bem" antes de pensar em tocar com o máximo desempenho. O público nem sempre procura a perfeição, mas sentir a emoção do intérprete, isso gera respeito. 


\section{Estratégia Cognitiva Comportamental}

A forma de o sujeito pensar sobre a situação temida é uma das causas da ansiedade de performance musical (APM). Tratar o comportamento de um músico ansioso é transportá-lo de pensamentos negativos à pensamentos positivos ou à reorganização cognitiva de seus hábitos durante a apresentação. Um dos estudos abordados é o de Kendrick et. al. (1982 apud WILSON E ROLAND, 2002), chamado treinamento da atenção. A um grupo de 53 pianistas apresentando APM, foi solicitada a identificação de pensamentos negativos, percebidos durante a performance, e a substituição desses pensamentos por mentalizações otimistas. Os autores utilizaram elementos como persuasão verbal, instrução, realização de apresentações e exercícios individuais. A melhora se percebeu na prática repetida entre amigos e público de apoio. Outra pesquisa forneceu um estudo de terapia cognitiva contra tranquilizantes, quando se observou que a prática controlada de exercícios de relaxamento reduziu o uso desses ansiolíticos.

Uma prática comportamental conhecida no tratamento da ansiedade no recital é a de sensibilização sistemática, que envolve o treino de relaxamento muscular, seguido do mental. Por exemplo, um pianista ansioso imagina-se tocando uma peça fácil na presença de familiares. Assim, passa a um cenário mental que inclui a presença de alguns estranhos até imaginar-se em um grande concerto. Essa teoria tem base no medo que produz um estado de repulsa pelo objeto temido, então é necessário persuadir o ansioso a encontrar-se com esse objeto em etapas graduais (Idem, 2002).

\section{Estratégia de relaxamento}

Um estado relaxado caracteriza-se pela não existência de atividades desnecessárias ou qualquer sensação de deficiência durante um período de tempo. Em termos de performance musical, técnicas de relaxamento podem ser usadas para: 1. gerenciar o nível de alta excitação, que pode interferir o pré, o durante e 
o pós funcionamento da performance; 2. controlar a vida em geral e evitar estresse físico e psicológico (WILLIAMON, 2004).

De acordo com o parecer do autor citado, alunos de música têm produzido resultados notáveis quando se utilizam intervenções cognitivocomportamentais para reduzir o "medo do palco" geralmente associado à excitação física, mental e emocional. Embora o nível de excitação adequado para que uma apresentação varie entre indivíduos, o treino de relaxamento possibilita incutir uma consciência corporal e um estado mental relaxado. Essa consciência pode reduzir a tensão muscular, que interfere na coordenação de habilidades físicas, ou acalmar a mente.

A profundidade de relaxamento vai depender do tempo e da concentração dedicados ao exercício. Já a prática de métodos mais profundos de relaxamento é melhor realizada após a atividade musical, e não antes, ou após sessão de treinos intensivos e, mais comummente, como parte de uma rotina diária; antes de dormir, por exemplo, quando podem ser particularmente benéficos no combate à fadiga e à preocupação em excesso.

O abrandamento momentâneo pode ser usado em relação à performance musical de várias maneiras: antes do aquecimento no instrumento, para determinar um sentido físico, mental e emocional; em intervalos durante a prática, para reduzir a tensão desnecessária e reorientar reflexões sobre a atividade; como parte do aquecimento para baixo, a fim de reduzir o acúmulo de tensões e restabelecer um estado físico equilibrado; e antes de praticar qualquer forma de ensaio mental.

Com base na diferenciação desses dois conceitos, conseguiu-se compreender quais habilidades já haviam se tornado um hábito, e quais as estratégias utilizadas para chegar a determinado conhecimento. Ou seja, dentro das habilidades que os participantes dispunham, quais estratégias, foram utilizadas para alcançar o objetivo, no caso a segurança no repertório e execução do recital com o mínimo de ansiedade. 


\section{Procedimento metodológico}

A pesquisa, realizada em Recife-PE, foi de cunho qualitativo do tipo estudo multicaso, cujos participantes foram seis pianistas, divididos em dois grupos: três estudantes da Escola Técnica Estadual de Criatividade Musical (ETECM) e três pianistas profissionais. Os instrumentos de coleta de dados foram entrevista semiestruturada antes e após o recital, roteiro de estudo, gravações, questionário de comportamento e de ansiedade. A partir da aplicação dos instrumentos de coleta (entrevistas, roteiro e gravações) foram identificadas e classificadas as habilidades e estratégias utilizadas pelos participantes antes, durante e após o recital; e com base nos questionários aplicados constatamos quais sentimentos e comportamentos foram percebidos pelos participantes uma semana antes e durante o recital.

Explanaremos a seguir, um quadro comparativo entre estudantes e profissionais das habilidades utilizadas para a amenização da ansiedade no palco.

QUADRO 1: Quadro das habilidades utilizadas antes, durante e pós-recital pelos sujeitos da pesquisa

\begin{tabular}{|l|l|}
\hline \multicolumn{1}{|c|}{ PROFISSIONAIS } & \multicolumn{1}{c|}{ ESTUDANTES } \\
\hline $\begin{array}{l}\text { Habilidade perceptiva das diferentes } \\
\text { memórias que interagem numa execução: } \\
\text { mental, auditiva, visual, digital e tátil }\end{array}$ & xxxxxxxxxxxxx \\
\hline Habilidade de preparação & Habilidade de preparação \\
\hline Habilidade de ensaio & Habilidade de ensaio \\
\hline Habilidade de avaliação musical & Habilidade de avaliação musical \\
\hline Habilidade da repetição consciente & xxxxxxxxxxxx \\
\hline Habilidade técnica & Habilidade técnica \\
\hline Habilidade interpretativa & Habilidade interpretativa \\
\hline Habilidade de memorização & Habilidade de memorização \\
\hline Habilidade de concentração & Habilidade de concentração \\
\hline Habilidade de performance musical & Habilidade de performance musical \\
\hline Habilidade pedagógica & xxxxxxxxxxxxx \\
\hline Xxxxxxxxxxxx & Habilidade de pensamento positivo \\
\hline
\end{tabular}


As habilidades encontradas nos estudantes não se apresentaram no mesmo estágio que nos profissionais, nem poderiam, pois, segundo Sternberg (2008), os esquemas dos especialistas envolvem unidades maiores de conhecimento e altamente interconectadas, já os esquemas dos novatos envolvem unidades de conhecimento relativamente pequenas e superficiais, porém, na visão da pesquisadora, com grande possibilidade de crescimento.

Cada habilidade encontrada nos participantes foi classificada de acordo com os estágios de desenvolvimento propostos por Anderson (1982). ${ }^{6}$ São eles, o cognitivo, o associativo e o autônomo, mas sem realizar comparações sobre a qualidade de cada uma, e sim a eficiência de atuação. Discorreremos sobre as habilidades de ensaio, de gravação, de performance musical e de concentração.

\section{Habilidade de ensaio}

Apesar de todos os participantes terem relatado suas estratégias de ensaio, percebemos que nos profissionais houve automatismo em razão dos anos de prática. Um deles faz a relação com a rotina de estudos quando era estudante e nos dias de hoje. Antes praticava quatro a cinco horas diárias, hoje duas horas e meia, aproximadamente. Exceto em épocas próximas a recitais. E acrescenta:

Eu tenho o costume de sempre estudar antes, bem antes pra um recital, porque à medida que vai chegando o dia, eu vou estudando menos, pra não ficar aquela afobação de que tem de sair; tenho um conceito a respeito: se não ficou bom até um mês antes, não sai mais. Pode melhorar. Tecnicamente você tem de ter vencido o que vai tocar com um mês de antecedência, no máximo (PROFISSIONAL 1).

Desse modo entendeu-se que graças aos anos de prática, esse profissional adquiriu habilidades técnicas e musicais que possibilitam a diminuição de seu tempo de estudo.

De acordo com Sloboda (2008, p. 285), um dos conceitos associados à aquisição de habilidades é a aquisição de hábitos, cuja principal característica é o

\footnotetext{
${ }^{6}$ apud Sloboda, 2008, p. 286
} 
seu automatismo e a pouca ou nenhuma capacidade mental para executá-lo. Outra condição fundamental para o aprendizado de habilidades é a repetição. Pessoas podem se tornar hábeis em determinada tarefa quando se lhes apresentam sucessivas oportunidades de envolver-se com os elementos constituintes. Amplia-se o conhecimento quando a atividade é realizada repetida vezes e com sucesso.

\section{Habilidade de gravação}

Outra sugestão do profissional 2 é a prática de gravações. Segundo ele, quando alguém é filmado, a sua ação fica mais focada, mais atenta.

Eu também gravo muito, mas, assim, gravando sem interrupções. Isso já te dá aquela responsabilidade, "é agora". Quando você está estudando, você repete, você para, nunca toca do começo ao fim, então quando a peça já está estudada, eu procuro sempre tocar a peça inteira sem interrupção e depois é que eu estudo.

Greene (2002, p. 113), sugere que não é necessário fazer a gravação de todo o repertório do recital, escolher pelo menos três peças. A ideia é estar preparado para o momento da filmagem. O autor destaca: "Confie e siga em frente, quando estiver pronto, execute toda a peça e faça alguns comentários sobre a gravação antes de desligar, anotando as ideias em seu registro; caso não esteja satisfeito com os resultados, sinta-se livre para fazer mais uma tentativa".

\section{Habilidade de performance musical}

Sloboda (2008, p. 87) a conceitua assim: “aquela na qual um executante ou um grupo de executantes interpreta música conscientemente para um público". Ray (2005) acrescenta que é o momento em que o músico se expõe à crítica do outro. Compreendemos que essa habilidade foi utilizada tanto por estudantes e profissionais. Na análise, observamos que as experiências de palco anteriores dos estudantes, como minirrecital e audições, possibilitaram um bom desempenho no 
recital, cuja ação ocorreu automática e confiantemente, mesmo percebendo que o comportamento no palco do estudante 1 deve ter sido marcado pela emoção. Posteriormente o participante revelou, em entrevista, associação com elementos extramusicais que, provavelmente, tenham sido a motivação maior para ele conseguir conduzir a execução até o final.

Todavia a emoção que o intérprete pode transmitir não é só a pessoal, mas também a emoção originada da própria música. Cada harmonia, sequência de notas, ritmo ou combinação de sons pode ser associado a uma emoção, ou seja, independentemente do sentimento pessoal, questões estéticas e estruturais de uma obra podem comunicar algum tipo de sensação no ouvinte (LISBOA; SANTIAGO, 2006). O profissional 1, por sua vez, revelou ter iniciado a prática em recitais desde os 10 anos de idade. O segundo profissional também afirmou ter experiência de palco há muitos anos e, mesmo a ansiedade presente na véspera da apresentação, isso nunca o impediu de tocar. O profissional 3 revelou que apesar de anos de prática pianística, na sua percepção, as oportunidades de execução pública foram insuficientes e, por consequência, afirma sentir ansiedade nessas ocasiões.

\section{Habilidade de concentração}

Segundo Greene (2002), a concentração é uma necessidade absoluta para artistas interessados em desenvolver o seu melhor, no entanto, as condições físicas, psicológicas, emocionais e ambientais são fatores que influenciam a qualidade e intensidade da concentração. Na visão do profissional 2 é imprescindível a prática da concentração nos períodos de ensaio, para que, no momento da performance musical, ela seja utilizada com todo o potencial necessário para um desempenho em público. O músico deve adquirir esse hábito para que fique "extremamente concentrado naquilo que está fazendo e não deixe a ansiedade atuar", afirma ele. Acrescenta que o estudo lento e concentrado são aspectos que amenizam a ansiedade. 
Quando questionamos a um dos profissionais se algo lhe tirou o foco durante a execução pianística ele responde: "não, nada me tira a concentração, a não ser se um morcego passar por cima de minha cabeça, porque morro de medo" [risos]. Já os estudantes, compreendemos que esta habilidade ainda estava em fase de desenvolvimento, segundo constatamos em seus relatos sobre os pensamentos que permeavam a mente um pouco antes de entrar no palco: o primeiro preferiu não pensar em nada, o segundo, porém, preocupava-se com o público que o aguardava, já o terceiro buscou desenvolver pensamento positivo. No entanto, enquanto o estudante 2 permaneceu com o mesmo pensamento durante a apresentação, os estudantes 1 e 3 desenvolveram pensamentos extramusicais para auxiliá-los musicalmente.

Sobre a concentração, indagamos aos estudantes se houve concentração durante o recital. 0 estudante 1 alegou que sim, mas a ansiedade foi o único fator que the tirou um pouco o foco. Mesmo assim, revela que "tava focado ali pra tocar"; O estudante 2 discorre : “Ah, teve alguém que, de vez em quando, falava aqui no auditório e era uma voz feminina". E continua:

Um momento eu estava concentrado numa hora e aí eu pegava e desconcentrava e tipo, errava, esbarrava, aí voltava, mas eu não estava completamente dentro, eu tava meio que aéreo, eu tava me sentindo como se eu estivesse numa corda bamba, eu não estava nem lá, nem cá, meio sem entender.

O estudante 3 respondeu que apenas da terceira música em diante sentiuse mais concentrado. Insistindo, foi questionado se algo o havia tirado do foco, ao qual ele respondeu que nada lhe tirou a concentração, apenas o barulho do ar, sem impedir de focar-se.

Gallwey (2008, p. 13), dá algumas recomendações sobre o hábito da concentração:

Desenvolver a habilidade mental envolve a aprendizagem de, pelo menos, três habilidades internas: 1) aprender como obter a imagem dos resultados almejados de forma mais clara possível; 2) aprender a confiar em si mesmo, seja no sucesso ou no fracasso e 3) aprender a visualizar "sem julgamento", isto é, mentalizar previamente o que está para acontecer em vez de ficar 
como um expectador, meramente observando o que está ocorrendo de bom ou de ruim.

Para Greene (2002), a concentração no momento do recital envolve três aspectos: intensidade, presença e duração do foco. A intensidade depende de outras variáveis como preparo e descanso, pois, quanto mais tempo houver nas exigências da situação, maior será a necessidade do fluxo (outflow) de energia. Para que o pico de foco em uma apresentação inteira seja mantido, é necessário dosar a energia com prudência, a fim de tê-la disponível ao final. A presença de foco refere-se à capacidade de manter a atenção no aqui e agora. O músico que possui essa competência não se lamenta por algumas notas erradas durante a performance, ele permanece focado no que faz. Por outro lado, a categoria duração do foco refere-se à distância em que o instrumentista mantém a concentração. Na maioria das vezes, esse tempo depende das circunstâncias e da quantidade de energia mental utilizada. Pela fala dos participantes, identifica-se que a presença de foco não foi efetiva, no entanto, o estudante 3 afirmou que, após certo tempo, conseguiu atingir a concentração necessária.

Outras habilidades encontradas na preparação e apresentação do recital foram: Habilidade de avaliação musical, Habilidade cognitiva ou de pensamento positivo (estágio cognitivo); de preparação e concentração (estágio associativo); habilidade de memorização, Técnica, Habilidade interpretativa, de repetição consciente, Habilidade perceptiva das diferentes memórias que interagem numa execução, de performance musical e pedagógica (Estágio autônomo).

Segundo Anderson (1982 apud SLOBODA, 2008) as habilidades vão se desenvolvendo com o treinamento e, à medida que vão progredindo, alcançam novos estágios. Dessa maneira, o estágio cognitivo é o início do desenvolvimento da aprendizagem e o aprendiz está gerando um comportamento. Há mediações verbais em que o aluno utiliza a repetição na execução da habilidade. Ao passar para o estágio associativo, a habilidade é executada de maneira suave, os erros são detectados e eliminados gradativamente. Quando as habilidades são incorporadas mediante as regras de produção, ou seja, quando vão sendo 
automatizadas, passam para o estágio autônomo e as habilidades alcançam uma melhoria gradativa e continuada indefinidamente.

A seguir, apresentamos o quadro das estratégias percebidas no período antes, durante e pós-recital, as quais, sob a compreensão da pesquisadora, auxiliaram direta ou indiretamente na amenização da ansiedade.

Quadro 2: Quadro das Estratégias utilizadas antes, durante e pós-recital pelos sujeitos da pesquisa

\begin{tabular}{|c|c|}
\hline PROFISSIONAIS & ESTUDANTES \\
\hline Estratégia de planejamento de estudo & Estratégias de planejamento de estudo \\
\hline $\begin{array}{l}\text { Estratégia de amadurecimento do } \\
\text { repertório }\end{array}$ & Estratégia de amadurecimento do repertório \\
\hline $\begin{array}{l}\text { Estratégia para manter o interesse no } \\
\text { repertório }\end{array}$ & Xxxxxxxxxxxxxxxxxxx \\
\hline $\begin{array}{l}\text { Estratégia de repetição consciente do } \\
\text { programa }\end{array}$ & Xxxxxxxxxxxxxxxxxx \\
\hline$x x x x x x x x x x x x x x x x x x x x x$ & Estratégia de recuperação \\
\hline $\begin{array}{l}\text { Estratégia de reelaboração } \mathrm{da} \\
\text { interpretação musical }\end{array}$ & $\begin{array}{l}\text { Estratégia de reelaboração da interpretação } \\
\text { musical }\end{array}$ \\
\hline $\begin{array}{l}\text { Estratégia de adaptação ao repertório } \\
\text { completo }\end{array}$ & $\begin{array}{l}\text { Estratégia de adaptação ao repertório } \\
\text { completo }\end{array}$ \\
\hline Estratégia de simulação do recital & $\begin{array}{|lccc|}\begin{array}{l}\text { Estratégia de simulação } \\
\text { (pseudoaudição) }\end{array} & & & \text { recital } \\
\end{array}$ \\
\hline $\begin{array}{l}\text { Estratégia de prática no instrumento e } \\
\text { percepção sonora da acústica do ambiente }\end{array}$ & $\begin{array}{l}\text { Estratégia de prática no instrumento e } \\
\text { percepção sonora da acústica do ambiente }\end{array}$ \\
\hline Estratégia de gravação durante ensaios & Xxxxxxxxx \\
\hline Estratégia de preparação (semana anterior) & Estratégia de preparação (dia anterior) \\
\hline Estratégias de amenização da ansiedade & Estratégias de amenização da ansiedade \\
\hline Estratégia de concentração & Xxxxxxxxx \\
\hline Estratégia de relaxamento & Xxxxxxxxx \\
\hline Estratégia de administração do tempo & Xxxxxxxxx \\
\hline Estratégia de preparação física & $X x x x x x x x x$ \\
\hline$x x x x x x x x x x$ & Estratégia cognitiva \\
\hline$x x x x x x x x x x$ & Estratégia para estabelecer objetivos e metas \\
\hline
\end{tabular}

Jorgensen (2004) aponta três fases de aprendizagem para uma prática instrumental eficaz: 1) Planejamento e preparação; 2) Execuções da prática; 3) 
Observação e avaliação. As respectivas fases de prática são entrelaçadas e cíclicas, ou seja, não há uma hierarquia entre elas, mas constantes reelaborações e feedback.

As estratégias que auxiliaram na amenização da ansiedade de forma indireta foram: de relaxamento, de repetição consciente do programa, de administração do tempo para manter o interesse no repertório, de adaptação ao repertório completo e de preparação física, todas detectadas nos profissionais, podem não ter ligação direta com a amenização da ansiedade, mas foram referidas por estudiosos sobre a influência que possuem durante a preparação e a correta administração para uma performance (JORGENSEN, 2004; SLOBODA, 2008; RAY, 2009; WILLIAMON, 2004). Já as estratégias de prática no instrumento, a cognitiva, a de simulação do recital e a própria estratégia de amenização da ansiedade estiveram mais diretamente ligadas ao auxílio da minimização dessa sensação. As estratégias encontradas foram divididas de acordo com as três fases de aprendizagem propostas por Jorgensen (2004).

De acordo com a sugestão do autor classificamos as estratégias encontradas da seguinte forma: 1) Planejamento e preparação da prática: Estratégia de planejamento de estudo ou de ensaio ${ }^{7}$, para estabelecer objetivos e metas, de relaxamento, de amadurecimento do repertório, de manutenção do interesse no repertório, Estratégia da repetição consciente do programa, de preparação, de prática no instrumento e percepção sonora da acústica do ambiente, de administração do tempo, de preparação física e Estratégia de concentração; 2) Execuções da prática: Estratégia de amadurecimento do repertório, Estratégia de pseudoaudições (ou simulação de um recital), Estratégia de adaptação ao repertório completo, Estratégia de simulação do recital, 3) Observação e avaliação da prática: Estratégia de gravação, Estratégia de

\footnotetext{
${ }^{7}$ Jorgensen classifica a estratégia de ensaio na segunda fase, a de execução da prática. Nós optamos por classificá-la na primeira fase de planejamento e preparação da prática, e a fase de execução referindo-nos ao momento em que o músico tem a oportunidade de executar o repertório completo ou a sua maior parte em algumas situações que gerem ansiedade como a simulação do recital e a pseudoaudição.
} 
recuperação, Estratégia cognitiva (ou de pensamento positivo), Estratégia de amenização da ansiedade. ${ }^{8}$

Destacaremos a seguir as estratégias de simulação do recital, de preparação para o recital, de prática no instrumento e percepção sonora da acústica do ambiente e de recuperação.

\section{Estratégia de simulação do recital (pseudoaudições)}

A estratégia de simulação do recital foi uma sugestão tanto de profissionais como estudantes. De acordo com Fonseca (2007), a relação entre o artista e seu público é uma experiência muito pessoal, que surge da interação entre o músico, das suas experiências passadas e do contexto atual de performance, bem como da natureza da audiência. Para que o pianista consiga vencer o desafio de enfrentar um público, às vezes desconhecido, o profissional 2 Sugeriu uma solução:

O que pode ajudar é fazer pequenos recitais, começar a dividir isso que você vai fazer na hora do concerto, um pouco antes. Você vai tocar, fazer um concerto, mas pra um grupo pequeno, pra um amigo ou um grupo de amigos, ou mesmo você se gravar, isso ajuda muito.

A realização de pequenos recitais na presença de amigos também é uma solução sugerida por Cardassi (2000), que define essas apresentações como "prérecitais" e, segundo o nome diz, é o momento em que o pianista simula uma situação de recital, na presença de um pequeno público, preferivelmente de amigos e familiares, experimentando até circunstâncias de estresse. Também perguntamos aos estudantes se a prática de pseudoaudições $^{9}$ ajudaram-nos a sentir-se mais seguro no recital:

${ }^{8}$ Em relato de profissionais, as condições de segurança na preparação, concentração e busca de prazer no que se faz foram aspectos sugeridos como amenizadores de ansiedade. De igual modo, um estudante declarou que diminuir o ritmo de estudo na véspera do recital minimiza o nervosismo da apresentação, o que não ocorria anteriormente.

${ }^{9}$ A pseudoaudição é uma atividade escolar criada pelos próprios alunos, na qual se simula uma apresentação real no auditório da escola, onde eles têm a oportunidade de praticar no ambiente e no piano em que ocorrerá a futura apresentação, com o objetivo de se sentirem 
Professora, nós, alunos, sempre conversávamos sobre nosso medo do palco, sobre o nervosismo que sentíamos nas audições e também que não nos sentíamos muito 'familiarizados' com o piano, com publico e principalmente com a sensação estranha de estar no palco. Então a Pseudoaudição surgiu com base nesse nosso medo e insegurança. Foi uma forma que achamos de praticar e conversar um com outro, como nos sentíamos nas audições e assim compartilhar com os amigos que esse sentimento não é uma coisa única, que todos passam por isso, inclusive os nossos professores e os pianistas que a gente tanto 'idolatra'. Então se os grandes podem, por que nós, alunos, que estamos aprendendo, não podemos também?(ESTUDANTE 2)

Continua relatando que eles procuram ajudar-se mutuamente, compartilhando aspectos positivos para o momento da audição, como se portar diante do público, além de aproveitar o instrumento do auditório, um piano 1/4 de cauda, porque este não está sempre disponível para estudo e, segundo ele, ao tocarem, estranham um pouco. Dando continuidade, declarou: "Conversamos também sobre a forma que cada um tem de se concentrar e tentamos influenciar um ao outro com coisas boas e sentimentos bons". Sobre o nervosismo, ele sinalizou: "Percebi que, com o tempo e depois das 'pseudos', eu fui sentindo o nervosismo um pouco diferente. Por já ter subido tanto ao palco, conversado com os amigos sobre aquele momento, eu acho que foi desmistificada muita coisa que me dava medo". Então finaliza: “Nesse ensaio, podemos nos sentir à vontade e já que é impossível jogarmos fora o nosso medo, que ao menos possamos domá-lo, encarando o palco e a audição como uma coisa, normal!" [risos]

\section{Estratégia de preparação para o recital}

Ray (2009, p. 162) aborda que “mesmo quando o músico está em cena e possua qualidade, talento e formação sólida, é necessária a preparação para lidar com a situação de performance, e quanto melhor essa preparação, menor o grau de ansiedade". Indagamos aos participantes como se prepararam na última semana do recital. O profissional 1 responde: "Cada vez toco menos, se eu preparo o recital, não fico naquela ansiedade de estar estudando, estudando. Vou

mais bem preparados para o dia da audição ou recital. Nessa atividade, eles pedem que os professores não estejam presentes. 
estudando devagarzinho, um dia eu estudo, vamos dizer, duas peças, pra justamente não cair nessa de ficar com raiva do programa, entendeu?"

Percebemos, ainda, uma estratégia de amenização da ansiedade, que é a diminuição do tempo de estudo à medida que se aproxima o evento e a consciência da realização de um trabalho bem feito. Conforme afirma Greene (2002), à proporção que o dia do recital se aproxima, é necessário preparar-se física e mentalmente para o melhor desempenho na apresentação, diminuindo o tempo de treinamento e assim reservar energia para o grande momento. Já o profissional 2 declara:

Na última semana, eu procuro tocar mais as peças num tempo mais lento, com toda a expressão, estudar não, tocar, como se fosse câmera lenta. Porque isso já vai exagerando nas pausas entre as frases, eu gosto muito de fazer isso, já vai te acalmando. Quando você toca, a sua adrenalina já tá ali ativada e se você já fez isso em casa, seu corpo já tá acostumado, então você não tem aquela tendência de subir muito, sair atropelando, né? Você já sabe tudo que vai fazer, é mais pra estar em contato, [...] porque essa coisa de ansiedade também tem a ver com a concentração. Se você está extremamente concentrado naquilo que tá fazendo, não dá tempo, não te dá chance pra a ansiedade atuar.

\section{Estratégia de prática no instrumento e percepção sonora da acústica do ambiente}

Quase a totalidade dos músicos instrumentistas tem a possibilidade de executar sua apresentação no próprio instrumento de estudo, já os pianistas não têm essa opção. Eles utilizam o instrumento que se encontra no auditório onde será realizado o recital, o qual, na maioria das vezes, é um piano 1/4 de cauda ou 1/2 meia cauda. Todavia o piano que o recitalista estuda diariamente, em geral, é um piano de armário, cujo som é apropriado para ambientes pequenos. Já o instrumento $1 / 4$ de cauda, por exemplo, possui amplitude sonora maior, teclas um pouco mais largas e dois pedais, com funções específicas, além do lugar onde se posiciona a partitura, um pouco mais acima da visão do pianista, diferentemente do piano de armário, em que a partitura fica bem a frente de sua visão. 
Outro aspecto importante é a percepção da acústica do local. Nem sempre é possível o intérprete se preparar no ambiente da apresentação, porém estudiosos afirmam (RAY, 2005;2009, CARDASSI, 2000; KENNY, 2011) ser imprescindível que o intérprete tenha a percepção sonora apropriada a uma acústica de auditório, bem diferente da sala de estudo, além da visualização do recital que esse momento proporciona. Todos os pianistas utilizaram essa estratégia que, segundo Ray (2009), são aspectos fundamentais de preparação para amenização da ansiedade. Segundo Sloboda (2008, p. 298), “O retorno, no caso sonoro, é essencial para o sistema adaptativo, a fim de evitar produções fracassadas ou potencialmente danosas".

\section{Estratégia de recuperação}

Esta foi uma estratégia que observamos apenas no primeiro grupo, em dois dos estudantes. Um deles relata que o nervosismo nunca o impediu de tocar e que, apesar de eventualmente surgirem erros, segue executando sua apresentação, pois segundo ele, "se você parar e respirar, você já perde". Sinalizando uma concordância com Greene (2002), o autor sugere que o instrumentista não se prenda ao erro, porque atrasa a recuperação e, quanto mais o músico compreender o que geralmente ocorre após esse fato, imediatamente surge uma solução para que ele se recupere.

\section{Considerações finais}

O objetivo geral desta pesquisa foi investigar as habilidades e estratégias utilizadas por pianistas para a gestão da ansiedade nas apresentações. Nesse sentido, a pesquisa proposta trouxe uma abordagem comparativa de profissionais e estudantes, em que foram realizadas descobertas a respeito da limitação e do sucesso de ambos os participantes antes, durante e após o recital, proporcionando assim a contextualização do conhecimento. 
Valendo-nos das análises dos dados, inferimos que tanto estudantes como profissionais sentiram ansiedade antes e durante a performance. Apesar de interferir minimamente no desempenho, não foi motivo impeditivo da execução, por isso a ansiedade atuou de forma positiva; descobrimos que os sujeitos utilizaram habilidades e desenvolveram estratégias mais convenientes para cada um, as quais possibilitaram a amenização do medo de palco de forma direta ou indireta.

Quanto a diferença entre habilidade e estratégia descobrimos que a primeira refere-se à aquisição de automatismos para a solução de problemas mais complexos, os quais permitem ao indivíduo enfrentar situações constantes e rotineiras da vida com agilidade, rapidez e economia de tempo e esforço, já a estratégia consiste no passo a passo para a aquisição de determinada habilidade. Para alcançar a habilidade de tocar um instrumento, por exemplo, o aluno precisa aprender uma série de aspectos como postura, leitura musical, fisiologia corporal, técnicas adequadas para executar o repertório, embora seja necessário ressaltar que a aprendizagem de qualquer habilidade não é uma receita pronta, é preciso passar do conhecimento declarativo (o que se conhece na teoria), para o conhecimento procedimental (o que se conhece na prática).

Após as análises, depreendemos que o músico deve estar consciente de que a ansiedade na dose certa é benéfica, pois ela é a preparação do corpo para um desafio que está por vir. Não obstante, na escolha do repertório, o pianista deve optar por algo que ele sinta prazer em tocar e definir metas a serem alcançadas durante todo o processo de estudo. Porém, por vezes, os estudos podem tornar-se entediantes, por isso a necessidade de encontrar estratégias para manter o interesse no repertório. Inferimos que um programa inseguro é um fator impeditivo para o músico sentir prazer no que executa. Uma peça insegura dá margem para a ansiedade atuar de forma negativa, pois impede a concentração e o envolvimento musical, além de bloquear aquilo que o instrumentista conseguiu construir no processo de estudo. Compreendemos que o pianista deve se perguntar constantemente se realmente tem prazer no que faz, pois, caso contrário, dificilmente conseguirá satisfazer a si mesmo e ao público. 
É de fundamental importância o músico procurar aperfeiçoar o repertório pelo menos um mês antes de sua apresentação e não esperar até a semana do evento para corrigir dificuldades. Ele deve procurar alcançar o ideal, pois, durante sua execução, é bem provável que seu rendimento diminua um pouco. Desenvolver o hábito da concentração, a mente focada mesmo nas rotinas de ensaio. Praticar simulações de recital, utilizando a imaginação para projetar-se tocando com prazer e sentindo a receptividade do publico e, previamente, na presença de amigos, a fim de adquirir experiência e ter a sensação real de uma apresentação.

Pensar e agir com confiança, mostrar para a plateia uma postura firme e convincente de quem está bem preparado. No entanto, não importa quão preparado esteja o músico para uma apresentação, por vezes haverá um episódio de distração. Esta pode se referir a pessoas indesejadas, por exemplo, ou então a algum fato acontecido durante a apresentação: quebra do ar condicionado, frio excessivo, conversa na plateia, roupa ou sapato incômodo ou atraso para o início do evento. Finalmente, apresentar-se em recital com o mínimo de ansiedade não é uma condição, e sim um processo. Tudo depende de como essa trajetória foi construída. Quanto mais prazer o pianista sentir pela construção de seu recital, maior será o resultado no palco.

\section{Referências}

CARDASSI, Luciane. Pisando no palco: prática de performance e produção de recitais. Belo Horizonte, n. 1, 2000. Disponível em: < http://www.soniaray.com/ LucianeCardassi\%28artigo\%29.pdf>. Acesso em 17jul2011.

FERREIRA, Aurélio Buarque de Holanda. Miniaurélio Século XXI escolar: o minidicionário da língua portuguesa. 4.ed. Rio de Janeiro: Nova fronteira, 2001. p. 297.

FONSECA, Carlos M. da. Ansiedade de Performance em Música - Causas, Sintomas e Estratégias de Enfrentamento. In: ANAIS DO SIMPÓSIO DE COGNICCÃO E ARTES MUSICAIS INTERNACIONAL, n.3. Salvador: EDUFBA, 2007, p. 242-249.

GAINZA, Violeta Hemsy de. Estudos de psicopedagogia musical. [trad. Beatriz A. Cannabrava]. São Paulo: Summus, 1988. 
GALLWEY, W. Timothy. The Inner Game of Tennis. The classic Guide to the Mental Side of Peak Performance. New York, NY.: The Random House Publishing Group. 2008.

GREENE, Don. Performance Sucess: performing your best under pressure. New York, NY: Routledge, 2002.

GREEN, L. How popular musicians learn a way ahead for music education. Brookfield: Ashgate, 2001.

ILARI, Beatriz. Cognição musical: origens, abordagens tradicionais, direções futuras. In: ILARI, Beatriz; ARAÚJO, Rosane Cardoso de (orgs). Mentes em música. Curitiba: DeArtes, UFPR, 2009. p. 13-36.

JORGENSEN, Harald. Strategies for individual practice. In: WILLIAMON, Aaron. Musical Excellence. Strategies and techniques to enhance performance. New York: Oxford University press, 2004. p. 85-103.

KENNY, Dianna T. The Psychology of Music Performance Anxiety. Oxford: Oxford University Press, 2011.

LISBOA, Christian Alessandro; SANTIAGO, Diana. A utilização das emoções como guia para a performance musical. In: CONGRESSO DA ASSOCIAÇÃO NACIONAL DE PESQUISA E PÓS-GRADUAÇÃO EM MÚSICA (ANPPOM), XVI, Brasília, 2006. Disponível em <www.anppom.com.br/anais/anaiscongresso_anppon-2006/ cdromposteres $>$ acesso em: 21.jan.2012.

MENDES, Dayse Christina Gomes da Silva. Habilidades e Estratégias para gerir a ansiedade antes e durante o recital: um estudo multicaso com pianistas estudantes e profissionais. 178f. (Dissertação de mestrado em Educação Musical) UFPB, João Pessoa, 2014.

PAULA, Lucas de; BORGES, Maria Helena Jayme. O ensino da performance musical: uma abordagem teórica sobre o desenvolvimento dos eventos mentais relacionados às ações e emoções presentes no fazer musical. Em Pauta: Revista do Programa de Pós graduação Stricto-Senso da Escola de música e Artes Cênicas da Universidade Federal de Goiás, Goiânia, v. 4, n. 1, p. 29-43, 2004.

RAY, Sonia. Considerações sobre o pânico de palco na preparação de uma performance musical. In: ILARI, Beatriz; ARAÚJO, Rosane Cardozo (org.). Mentes em Música. Curitiba: Deartes, 2009. p. 158-178.

SANTI, Alexandre de. Ansiedade positiva. GALILEU. Ed. Globo, p.14-47, Março 2012.

SLOBODA, John A. Aprendizagem musical e desenvolvimento: Treinamento e aquisição de habilidades. In: A mente musical: A psicologia cognitiva da música.[Trad. Beatriz Ilari e Rodolfo Ilari]. Londrina:EDUEL, 2008. p. 284-314.

WILSON, Glenn D; ROLAND, David. Performance anxiety. In: MCPERSON, Gary E.; PARCUTT, Richard Eds. The Science \& Psychology of music performance. Creative strategies for teaching and learning. New York, NY: Oxford University Press, 2002. p. $47-61$. 
WILLIAMON, Aaron. A guide to enhancing musical performance. In:WILLIAMON, Aaron. Musical Excellence. Strategies and techniques to enhance performance. New York: Oxford University press, 2004. p. 3-18. 